\title{
Review: intravenous metoclopramide is better than placebo for reducing pain in acute migraine in the emergency department
}

Colman I, Brown MD, Innes GD, et al. Parenteral metoclopramide for acute migraine: meta-analysis of randomised controlled trials. BMJ 2004;329:1369-73.

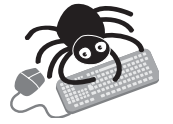

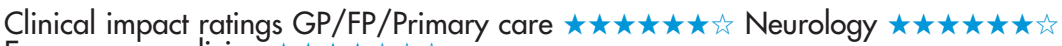
website

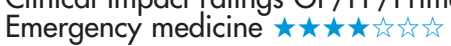

In patients with acute migraine, is metoclopramide more effective than a control intervention for reducing symptoms?

\section{METHODS}

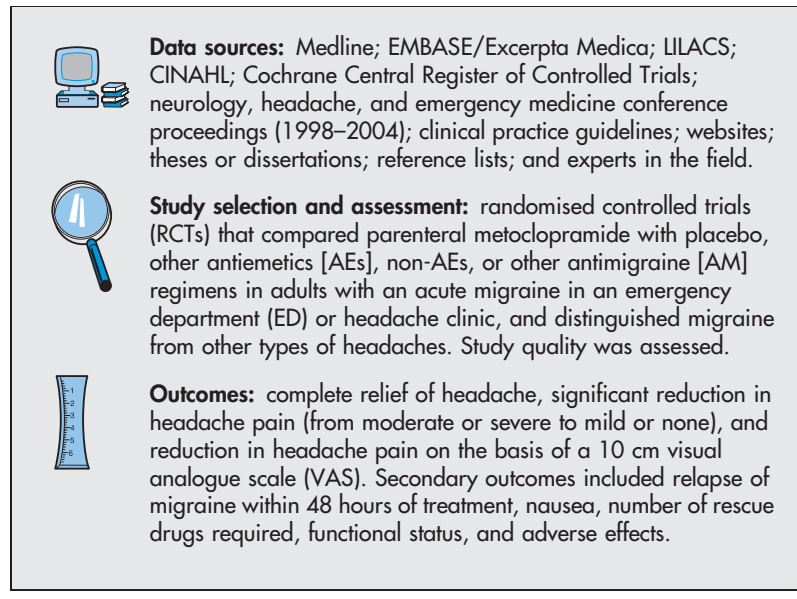

\section{MAIN RESULTS}

13 RCTs $(\mathrm{n}=655)$ met the selection criteria. 7 RCTs $(54 \%)$ were high quality (Jadad score $\geqslant 3$ ). Using a random effects model, metaanalysis of 3 RCTs showed that metoclopramide reduced headache pain (table), nausea (odds ratio [OR] 4.20, 95\% CI 1.70 to 10.36), and the need for rescue drugs (OR 0.21 , CI 0.05 to 0.85 ) more than placebo. The groups did not differ for complete relief of headache (see table at www.evidence-basedmedicine.com), relapse of migraine, or restlessness. 2 RCTs found that metoclopramide reduced headache pain less than other AEs (chlorpromazine and prochlorperazine) (table). The groups did not differ for complete relief of headache (see table at www.evidence-basedmedicine.com), pain scores on the VAS, relapse of migraine, nausea, or adverse events. Pooled results showed that patients in the metoclopramide groups were more likely to require rescue drugs than those in the other AE groups (OR 2.08, CI 1.04 to 4.17$)$. Of the 2 RCTs that compared metoclopramide with non-AEs, I RCT showed no difference between metoclopramide and sumatriptan for complete relief of headache (see table at www. evidence-basedmedicine.com), reduction in headache pain (see table For correspondence: Dr B H Rowe, University of Alberta, Calgary, Alberta, Canada. brian.rowe@ualberta.ca

Source of Funding: Canadian Institute of Health Research and Canadian Association of Emergency Physicians Research Consortium. at www.evidence-basedmedicine.com), or nausea (OR 19.74, CI 1.00 to 390.32). In another RCT, metoclopramide reduced the need for rescue drugs more than ibuprofen (OR 0.05 , CI 0.00 to 0.56 ). In studies comparing drug combinations, more patients achieved complete headache relief with metoclopramide combination than other AM regimens (table).

\section{CONCLUSIONS}

In patients with acute migraine, metoclopramide reduces headache pain. Compared with other single agents, metoclopramide shows variable effectiveness for reducing nausea, migraine relapse, need for rescue medication, functional status, and adverse effects.

Abstract and commentary also appear in ACP Journal Club.

\section{Commentary}

M etoclopramide avoids many perceived or actual liabilities of other current treatment choices for acute migraine. It also provides relief of pain and other such migraine associated symptoms as nausea and vomiting. These virtues explain the enduring popularity of metoclopramide for treating migraine in the ED setting.

Colman et al provided a good summary of evidence of the effect of metoclopramide. Although the results show a reduction in pain that favours metoclopramide over placebo, the duration of effect and rate of headache relapse is not known. Metoclopramide alone does provide definitive treatment for some patients; however, 3 of 4 patients on average will require alternative or adjunctive treatment. The severity of the migraine should dictate the approach to treatment in the ED. Ketorolac, sumatriptan, dihydroergotamine, chlorpromazine, prochlorperazine, and dexamethasone with or without metoclopramide can be considered for treatment of migraine in the ED.

The tantalising question of whether metoclopramide might outperform sumatriptan remains unanswered because the single study that reached this conclusion was low quality and lacked a placebo group. Some evidence supports the use of oral metoclopramide for acute migraine; ${ }^{1}$ however, the Food and Drug Administration recently rejected an application for an oral sumatriptan-metoclopramide combination product, stating concerns about long term safety. ${ }^{2}$ This should temper enthusiasm for wide scale use of metoclopramide.

Elizabeth W Loder, MD Spaulding Hospital, Boston, Massachusetts, USA

1 Pryse-Phillips WE, Dodick DW, Edmeads JG, et al. CMAJ 1997; 156:1273-87.

2 Prozen announces receipt of not-approvable letter for MT 100. www.pozen.com/product/mt100.asp (accessed 28 Jan2005).

Metoclopramide for acute migraine*

\begin{tabular}{|c|c|c|c|c|c|}
\hline Outcomes at 1 week & Number of trials ( $\mathrm{n}$ ) & Comparison & Weighted event rates & RBI $(95 \% \mathrm{Cl})$ & NNT (Cl) \\
\hline \multirow[t]{3}{*}{ Reduction in headache pain } & \multirow[t]{2}{*}{$3(185)$} & \multirow[t]{2}{*}{ Metoclopramide $v$ placebo } & \multirow[t]{2}{*}{$56 \%$ vs $31 \%$} & $80 \%(1$ to 221$)$ & $4(3$ to 44$)$ \\
\hline & & & & Odds ratio $(\mathrm{CI})$ & \\
\hline & $\begin{array}{l}2(161) \\
1(62)\end{array}$ & $\begin{array}{l}\text { Metoclopramide } v \text { other } A E \\
\text { Combination metoclopramic }\end{array}$ & other AMs & $\begin{array}{l}0.39(0.18 \text { to } 0.87) \\
7.79(1.79 \text { to } 33.86)\end{array}$ & \\
\hline
\end{tabular}

*Abbreviations defined in glossary; weighted event rates, RBI, NNT, and Cl calculated from data in article using a random effects model. †Not significant. 